\title{
PERANCANGAN ALAT TERAPI YANG ERGONOMIS BAGI ANAK PENDERITA CEREBRAL PALSY
}

\author{
Julianus Hutabarat ${ }^{1)}$, Renny Septiari ${ }^{2)}$ \\ 1,2 Program Studi Teknik Industri, Institut Teknologi Nasional Malang \\ E-mail: julianus1961@ lecturer.itn.ac.id
}

\begin{abstract}
Abstrak. Cerebral Palsy adalah berbagai perubahan yang abnormal pada organ gerak atau fungsi motor sebagai akibat dari kondisi tonus otot yang mengalami hipertoni. Letak kelainan ini terdapat pada sistem saraf pusat. Cerebral Palsy ditandai oleh adanya kelainan gerak, sikap atau bentuk tubuh gangguan koordinasi, terkadang juga disertai gangguan psikologis dan sensoris yang disebabkan oleh adanya kerusakan atau kecacatan pada masa perkembangan otak.

Tujuan utama dari penelitian ini adalah merancang sebuah alat terapi untuk penderita Cerebral Palsy dengan metode observasi mengenai stimulus koordinasi gerak antara tangan dan kaki pada anak yang diterapkan pada sistem mekanisme alat terapi, pengukuran antropometri dari penderita juga dibutuhkan untuk menentukan dimensi alat terapi, sehingga dapat digunakan secara nyaman dan aman bagi penderita sesuai dengan kaidah ergonomi. Perancangan ini diawali dengan pengumpulan data hasil kuesioner yang disebarkan kepada responden untuk mengetahui kriteria apa saja yang diinginkan oleh pengguna (Voice of Customer) dengan menggunakan skala Likert, uji validitas dan reliabilitas. Setelah didapatkan hasil dari kuesioner tersebut, maka diperoleh beberapa alternatif rancangan desain alat terapi bantu jalan yang sesuai dengan kriteria terpilih. selanjutnya dilakukan pengukuran dimensi alat terapi sesuai prinsip-prinsip ergonomis.

Hasil dari rancangan ini adalah alat terapi yang sesuai keinginan pengguna dan menghasilkan alat terapi yang ergonomis. Dimensi alat terapi secara keseluruhan dengan panjang $55 \mathrm{~cm}$ tinggi, lebar $45 \mathrm{~cm}$ dan $88 \mathrm{~cm}$,
\end{abstract}

Kata Kunci: Alat terapi, Cerebral Palsy, Ergonomi

\section{PENDAHULUAN}

Yayasan Pembinaan Anak Cacat (YPAC) Kota Malang, terutama bagi anak anak penderita penyandang cacat (difabel) diantaranya dan anak berkebutuhan khusus juga bagi penderita Cerebral palsy. Yayasan ini didirikan oleh dr. Tarekat Prawirowijoto bersama ibu-ibu yang peduli terhadap kesejahteraan sosial pada tanggal 24 Maret 1955, yang kemudian diketuai oleh Ibu Achmad Djohar.

Cerebral palsy atau palsi serebral merupakan suatu kelainan statis nonprogresif yang disebabkan oleh cedera otak pada periode prenatal, perinatal dan postural, yang berpengaruh pada ketidakmampuan untuk mengendalikan fungsi motorik, postur/sikap dan pergerakan yang disebabkan oleh kerusakan sistem saraf pusat penyebab terjadinya palsi serebral tidak hanya satu sehingga untuk mengetahui penyebab palsi serebral perlu digali lebih dalam mengenai jenis palsi serebal yang diderita, riwayat kesehatan ibu dan anak.

Dalam menjalankan terapi fisik, para terapis seringkali dibantu oleh alat- alat tertentu untuk mempermudah mereka dan anak penderita cerebral palsy dalam mencapai tujuannya. Hingga saat ini, alat terapi fisik yang ada jenisnya terbatas, dan setiap jenis biasanya hanya mampu digunakan untuk memenuhi sebagian kecil kebutuhan terapi para penderita cerebral palsy. Keterbatasan alat terapi yang ada saat ini menyebabkan anak-anak penderita cerebral palsy hanya dapat menjalani latihan terhadap satu bagian tubuhnya pada satu waktu.

Sementara itu, untuk memenuhi kebutuhan proses terapi selanjutnya, alat terapi fisik juga harus dapat mengakomodasi kebutuhan akan peningkatan kemampuan motorik dari beberapa bagian tubuh secara bersamaan. Rancangan alat terapi fisik harus pula disesuaikan dengan dimensi tubuh penggunanya, dalam hal ini adalah anak-anak penderita cerebral palsy jenis hemiplegia, diplegia, dan quadriplegia, dengan rentang usia 5 - 7 tahun. Hal ini disebabkan anak-anak pada rentang usia tersebut sedang mengalami pertumbuhan dan perkembangan fisik, sehingga apabila aspek ergonomi tidak diperhatikan dalam perancangannya, tentu akan menimbulkan gangguan pada anak. Selain itu, 
mengingat bahwa anak-anak penderita cerebral palsy juga mengalami masalah keseimbangan dan kurangnya pengendalian terhadap mobilitas anggota tubuhnya, maka rancangan alat terapi fisik yang aman sangat dibutuhkan. Oleh karena itu, dibutuhkan suatu perancangan alat terapi fisik bagi anak-anak penderita cerebral palsy yang memperhatikan aspek ergonomi (manfaat, keamanan, dan kenyamanan) yang disesuaikan dengan karakteristik dan kebutuhan khusus mereka dengan lebih mengutamakan penerapan perhitungan athropometri untuk penentuan dimensi alat terapi. Pemakaian data antropometri mengusahakan semua alat disesuaikan dengan kemampuan manusia bukan manusia disesuaikan dengan alat. Rancangan yang mempunyai kompatibilitas tinggi dengan manusia yang memakainya sangat penting untuk mengurangi timbulnya bahaya akibat terjadinya kesalahan kerja akibat adanya kesalahan desain. Pada hakekatnya hasil dari pengukuran tubuh yang diperoleh sangatlah penting dalam pengukuran dimensi fungsional karena berkaitan erat dengan gerakan-gerakan nyata yang diperlukan tubuh untuk melaksanakan setiap kegiatan tertentu. Dalam hal ini pengukuran jarak antara dua titik pada tubuh manusia yang ditentukan terlebih dahulu yang disesuaikan kebutuhan dalam desain produk, dimana jarak tersebut merupakan garis penghubung terpendek dipermukaan kulit atau lebih. Antropometri adalah alat ukur dengan satuan panjang centimeter yang dirancang secara khusus untuk digunakan tubuh manusia.

Penderita Cerebral Palsy ini tidak dapat disembuhkan total seperti anak normal akan tetapi mereka dapat dilatih dan diterapi agar dapat melakukan aktivitasnya sehari-hari sendiri sehingga tidak harus bergantung kepada keluarganya seumur hidup. Anak-anak penderita Cerebral Palsy melakukan terapi untuk memperbaiki keadaan fisik dan mental mereka sejak usia sedini mungkin karena pada usia-usia dini pembentukan tulang dan otot-otot mereka masih mudah dan dapat berubah walaupun tidak banyak.

Perancangan alat bantu jalan sekaligus alat terapi bagi anak penderita Cerebral Palsy yang sesuai kaidah ilmu ergonomi, diharapkan dapat mengurangi ketergantungan penderita meningkatkan kemandirian penderita untuk melangsungkan kehidupannya.

Secara statistik terlihat bahwa ukuran tubuh manusia pada suatu populasi tertentu berada disekitar harga rata-rata dan sebagian kecil hingga harga ekstrim jatuh di dalam dua distribusi. Hal ini mendasari sering digunakannya konsep rata-rata untuk memudahkan didalam melakukan perancangan, bila dibanding dengan penggunaan konsep range. Padahal suatu perancangan yang berdasar konsep rata-rata tersebut hanya akan menyebabkan sebesar $50 \%$ dari pengguna rancangan yang dapat menggunakannya dan sisanya tidak dapat menggunakannya. Oleh karena itu seharusnya tidak melakukan perancangan berdasarkan konsep rata-rata ukuran manusia. Karena melakukan perancangan berdasarkan konsep rata-rata ukuran manusia adalah tindakan yang kurang praktis dan umumnya membutuhkan biaya besar. Dari sinilah kemudian dilakukan penentuan range atau segmen tertentu dari ukuran tubuh populasi. Penggunaan data antropometri secara cermat tentunya sangat penting. Pemberian sejumlah penyesuaian kadang kala harus dilakukan agar tercipta suatu rancangan yang baik. Persentil antropometri pada individu, hanya didasarkan atas satu ukuran tubuh saja, seperti tinggi tubuh atau tinggi duduk. Tidak ada orang yang disebut sebagai orang yang persentil ke-50 atau persentil ke-5. Seseorang yang memiliki persentil ke-50 untuk tinggi mungkin dapat memiliki tinggi lutut pada persentil ke-40 atau panjang tangan pada persentil ke-50.

\section{METODE}

Responden pada penelitian ini adalah anak-anak penderita cerebral palsy usia antara 5-7 tahun sebanyak 15. Metodologi penelitian yang dilakukan sebelum merancang alat terapi yang ergonomis bagi anak-anak penderita cerebral palsy adalah :

1. Melakukan survey untuk mengamati proses aktivitas dan penanganan dari anak-anak penderita cerebral palsy

2. Melakukan pengumpulan dan pengolahan data antropometri untuk digunakan sebagai penentuan dimensi dari alat terapi bagi anakanak penderita cerebral palsy. Yang kemudian akan dilakukan uji keseragaman data dan kecukupan data.

3. Melakukan Analisa ergonomi: digunakan untuk mengetahui ergonomi dan posisi yang dapat memaksimalkan gerak dinamis saat beraktifitas. 
4. Pengukuran data antropometri bagian tinggi tubuh, tinggi siku berdiri, jangkauan tangan, lebar tangan

5. Menentukan kriteria desain untuk perancangan alat bantu jalan bagi anak-anak penderita cerebral palsy.

6. Melakukan analisa struktur dan bahan: digunakan untuk mengetahui kekurangan dan kelebihan dari masing- masing material agar aman dan nyaman ketika digunakan bagi anak-anak penderita cerebral palsy.

Observasi yang dilakukan selama di Yayasan Pembinaan Anak Cacat (YPAC) Kota Malang yakni dengan mengamati secara detil kegiatan pembelajaran dan terapi yang berlangsung antara pukul 08.00 WIB hingga pukul 15.00 WIB. Dari observasi ini didapatkan data berupa:

- Aktivitas bersosialisasi

- Aktivitas terapi fisik dan okupasi

- Aktivitas penggunaan alat bantu, termasuk orthosis

- Pola gerak penderita saat beraktivitas dan saat terapi

- Karakter psikologis orang tua

- Tahapan terapi yang diterapkan pada penderita Cerebral Palsy (CP)

\section{HASIL DAN PEMBAHASAN}

Penerapan antropometri pada alat bantu jalan bagi anak penderita cerebral palsy, sangatlah penting dengan mempertimbangkan bahwa tujuan utama dengan digunakannya alat bantu ini dapat mewujudkan kemandirian bagi anak tersebut. Dari analisis kebutuhan pelanggan dapat disimpulkan alternatifalternatif yang diinginkan konsumen. Adapun alternatif tersebut adalah sebagai berikut :

1. Alat yang dapat distel

Alternatif alat yang dapat distel disini dimaksudkan dapat diatur sesuai dengan ukuran pemakai. Untuk itu dari tiap part batang harus ada pengencang untuk pengaturan panjang pendeknya batang tersebut. Untuk pengencang disini menggunakan alternatif jenis klem dan baut.

2. Alat yang ringan

Alternatif bahan yang digunakan terbuat dari bahan kayu, besi dan almunium. Dari masing-masing bahan tersebut tentunya memiliki kelebihan dan kekurangan dalam pemakaiannya.
Pemodelan suatu produk akan mudah dilakukan dengan menggunakan Software berbasis Mechanical Desktop, sehingga model tersebut dapat disimulasikan melalui komputer dan resiko-resiko apabila produk tersebut dimodelkan secara manual dapat dihindari. Dimensi yang akan diterapkan pada alat bantu jalan/terapi mengacu pada antropometri tubuh anak normal (5-7 tahun) hal ini dengan pertimbangan bahwasanya anak penderita Cerebral Palsy sesungguhnya memiliki dimensi tubuh yang sama dengan anak normal, akan tetapi yang membedakan adalah kelemahan otot yang mengakibatkan penderita Cerebral Palsy tidak dapat bergerak seperti anak normal.

Anthropometri yang dipergunakan sebagai pedoman untuk memenetukan dimensi dari alat meliputi anthropometri :

a. tinggi bahu dalam posisi berdiri tegak, dengan pertimbangan untuk menentukan ketinggian alat.

b. Tinggi siku dalam posisi berdiri tegak, dengan pertimbangan untuk menentukan menentukan tumpuan telapak tangan pada alat.

c. Tinggi pinggul dalam posisi berdiri tegak, dengan pertimbangan untuk menentukan tumpuan telapak tangan pada alat.

d. Tinggi kepalan tangan terjulur ke bawah dalam posisi berdiri tegak dengan pertimbangan untuk tumpuan telapak tangan pada alat.

e. Tinggi ujung jari tangan terjulur lepas dalam posisi berdiri tegak, tumpuan telapak tangan pada alat (dimensi adjustable)

f. Lebar bahu dari kiri ke kanan, dengan pertimbangan untuk menentukan panjang alat

g. Lebar pinggul dari kiri ke kanan, dengan pertimbangan untuk menentukan panjang alat

h. Tebal dada dari depan sampai belakang, dengan pertimbangan untuk menentukan lebar alat.

i. Lebar jangkauan siku terbentang, dengan pertimbangan untuk menentukan dimensi space pada saat melakukan gerakan dinamis.

Berikut hasil persentile dari data antropometri yang dipergunakan pada perancangan alat terapi bagi anak penyandang cerebral palsy 
Tabel 1. Perhitungan Percentile anak usia $5-7$ tahun

\begin{tabular}{|c|l|c|c|c|}
\hline No & \multicolumn{1}{|c|}{ Jenis Antropometri } & \multicolumn{3}{|c|}{ Perhitungan Percentile (cm) } \\
\cline { 3 - 5 } & & $5 \%$ tile & $50 \%$ tile & $95 \%$ tile \\
\hline 1 & Tinggi bahu dalam posisi berdiri tegak & 75.91 & 87.58 & 99.25 \\
\hline 2 & Tinggi siku dalam posisi berdiri tegak & 58.19 & 67.43 & 76.67 \\
\hline 3 & Tinggi pinggul dalam posisi berdiri tegak & 50.41 & 60.09 & 69.78 \\
\hline 4 & Tinggi kepalan tangan terjulur ke bawah dalam posisi berdiri tegak & 38.89 & 47.17 & 55.45 \\
\hline 5 & Tinggi ujung jari tangan terjulur lepas dalam posisi berdiri tegak & 31.32 & 39.44 & 47.56 \\
\hline 6 & Lebar bahu dari kiri ke kanan & 22.26 & 28.11 & 33.97 \\
\hline 7 & Lebar pinggul dari kiri ke kanan & 18.15 & 23.93 & 29.70 \\
\hline 8 & Tebal dada dari depan sampai & 9.73 & 15.68 & 21.63 \\
\hline 9 & Lelakang & & & \\
\hline
\end{tabular}

Dari tabel diatas didapatkan ukuran persentile pengguna sesuai kebutuhan antropometri pada orthosis, dimensi mengacu pada ukuran $50 \%$ tile dimaksudkan supaya pengguna dengan ukuran tubuh 5\%tile maupun 95\%tile dapat menggunakan. Ukuran ini kemudian menjadi patokan dalam mendesain orthosis dan pada sistem adjustable.

\section{Kriteria desain alat terapi :}

a. Kenyamanan dalam penggunaan

b. Kemudahan operasional

c. Desain yang praktis digunakan

d.Bahan yang berkualitas dan kuat

e. Mudah untuk dipidahkan

\section{Spesifikasi alat terapi}

a. Tinggi $88 \mathrm{~cm}$, panjang $55 \mathrm{~cm}$ dan lebar 45 $\mathrm{cm}$.

b. Bahan terbuat dari alumunium

c. Bagian punggung dilapisi bahan spon dan busa

d.Roda terbuat dari karet yang tidak licin

e. Alat dapat diatur panjang dan pendek dengan fungsi stelan dari mur dan baut.

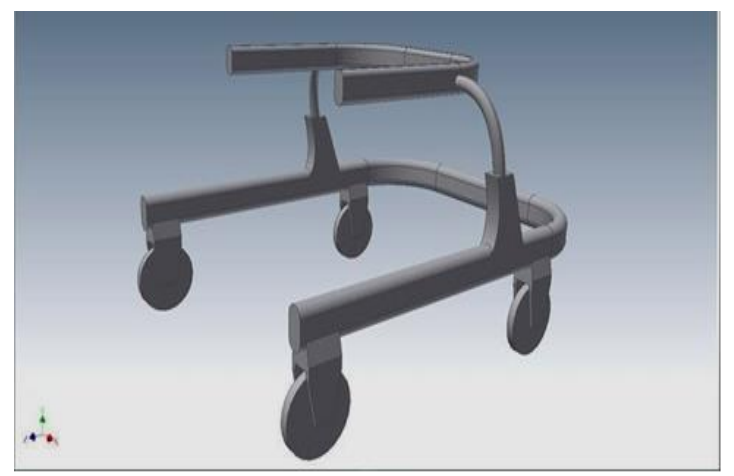

Gambar 1.Alat terapi

\section{KESIMPULAN}

Penerapan alat terapi bagi anak penderita Cerebral Palsy di Yayasan Pembinaan Anak Cacat (YPAC) Kota Malang belum sesuai dengan kebutuhan penderita karena terbatas fasilitas yang terdapat di yayasan tersebut, selain itu juga pelaksanaan yang kurang maksimal. Pengembangan yang dilakukan oleh sekolah dan terapis tidak lepas dari prinsip pengembangan terapi yang ada.

Dengan adanya peralatan terapi yang sesuai dengan dimensi tubuh pengguna diharapkan dapat membantu penderita anak penderita Cerebral Palsy saat beraktifitas berjalan sehingga dapat meningkatkan kualitas hidup dengan kemandirian. Adapun alat ini memiliki dimensi keseluruhan meliputi tinggi $88 \mathrm{~cm}$, panjang $55 \mathrm{~cm}$ dan lebar $45 \mathrm{~cm}$. Untuk lebih mengoptimalkan saat melakukan latihan gerakan kaki serta tangan maka pada alat ini juga dilengkapi dengan roda supaya lebih ringan untuk digerakkan.

Dengan adanya usulan desain alat terapi ini diharapkan dapat lebih meningkatkan mobilitas bagi anak penyandang cerebral palsy yang ada di YPAC.

\section{DAFTAR PUSTAKA :}

Davis, E., Shelly, A., Waters, E., \& Davern, M. 2010. Measuring the Quality of Life of Children with Cerebral Palsy: Comparing the Conceptual Differences and Psychometric Properties of three Instrument. Developmental Medicine and Child Neurology, 174-180.

Nakita. 2002, Memahami dan Menangani Anak dengan Kebutuhan Khusus (Cerebral Palsy), PT Sarana Kinasih Satya Sejati, Jakarta. 
Nurmianto, Eko. 2000. Ergonomi Konsep Dasar dan Aplikasinya. Surabaya. Guna Widya.

Palisano, Robert, Peter Rosenbaum, Stephen Walter, Dianne Russell, Ellen Wood, dan Barbara Galuppi. 1997. "Development and Reliability of a System to Classify Gross Motor Function in Children with Cerebral Palsy." Dev Med Child Neurol 113- 120.

Prasetyo Catur Utomo, S.Th Susilowati, Retno Azizah. Pengaruh Penggunaan Ankle Foot Orthose (AFO) Dan Backslab Terhadap Kualitas Hidup Pada Pasien Cerebral Palsy. Jurnal Kesehatan, Volume VIII, Nomor 1, April 2017, hlm 135-138.

Putu Cindy Pradnya Pratiwi,Baroto Tavip Indrojarwo. Desain Mainan Anak Khusus Penderita Cerebral Palsy Dengan Konsep Menstimulus Koordinasi Gerak
Anak. Jurnal Sains Dan Seni ITS Vol. 5, No.2, (2016) 2337-3520 (2301-928x Print)

Tarwaka. 2004. Ergonomi untuk Keselamatan dan Produktivitas. Surakarta. UNIBA Press.

Ulrich, Karl T. and Steven D, Eppinger. 2001. Perancangan dan Pengembangan Produk. Jakarta: Salemba Teknik.

Widodo, Imam Djati, 2005, Perencanaan dan Pengembangan Produk, UII Press, Yogyakarta.William Mendenhall, Statistics for engineering and The Sciences, third edition, Universitas of South Florida.

Wignjosoebroto, Sritomo. 2003, Ergonomi Study Gerak dan Waktu. Guna Widya Surabaya. 